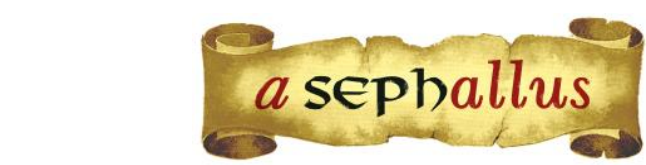

Revista aSEPHallus de Orientação Lacaniana

Núcleo Sephora de Pesquisa sobre o Moderno e o Contemporâneo

ISSN $1809-709 \mathrm{X}$

\title{
A pleonexia, o que é? ${ }^{1}$
}

Dany-Robert Dufour ${ }^{2}$

Filósofo

Professor da Universidade Paris VIII

Autor de A Cidade perversa (Ed. Civilização Brasileira), O divino Mercado (Ed. Companhia. de Freud), Os mistérios da trindade (Ed. Companhia. de Freud), $A$ arte de reduzir as cabeças (Ed. Companhia de Freud) e Le délire occidental (Éditions Les Liens qui libèrent).

E-mail: dany.dufour@free.fr

\begin{abstract}
Resumo: O texto é a introdução de um recente livro do filósofo francês Dany-Robert Dufour, o qual reúne produções apresentadas em um evento cultural - "Philosophie à vif" -, organizado no Teatro de la Têmpete, em junho de 2014. Neste texto, o autor apresenta a questão da pleonexia - desejo de possuir sempre mais como crucial para compreender o mundo atual, que se caracteriza pela hiperconcentração da riqueza. Para abordar o tema, Dufour selecionou para esse evento quatro textos filosóficos que foram adaptados e reescritos para serem lidos por grandes comediantes: dois textos de Platão ( $A$ República e Gorgias); $A$ fábula das abelhas, de Mandeville; no quarto texto, da autoria do próprio Dufour, cria-se um encontro entre Sócrates e seu interlocutor nos dias de hoje para fazer um balanço. Por fim, o anexo apresenta um texto exclusivo traduzido pela primeira vez em francês de autoria filósofo romeno Dimitre Cantemir, cujo original data de 1705, e contém uma importante reflexão sobre a pleonexia.
\end{abstract}

Palavras-chave: pleonexia; "mais de..."; pulsionalidade; psiquê; estrutura da alma; excesso; contemporaneidade.

\section{La pléonexie, qu'est-ce?}

Ce texte est l'introduction d'un récent livre du philosophe français Dany-Robert Dufour, lequel rassemble les productions présentées lors d'un événement culturel - "Philosophie à vif" -, qui a eu lieu au Théâtre de la Tempête, en juin 2014. Dans ce texte, l'auteur présente la question de la pléonexie - désir de posséder toujours plus - comme crucial pour comprendre le monde actuel, caractérisé par une hyperconcentration de la richesse. Pour aborder cette question, Dufour a choisi à cette occasion quatre textes philosophiques qui ont été adaptés et réécrits pour la lecture publique par grands comédiens: deux textes de Platon (La République et Gorgias); La fable des abeilles, de Mandeville; le quatrième texte est un dialogue socratique, écrit par Dufour lui-même, où Socrate discute avec son contradicteur aujourd'hui pour faire le point. Enfin, en annexe il y a un texte exclusif, traduit pour la première fois en français, de I'auteur roumain, Dimitre Cantemir, écrit en 1705, en menant une réflexion importante sur la pléonexie.

Mots-clés: pléonexie; "plus de..."; pulsionnalité; psyché; structure de l'âme; excès; contemporanéité.

\section{Pleonexia, what's it?}

The text is the introduction to a recent book by the french philosopher Dany-Robert Dufour, which brings together productions that were presented in a cultural event - "Philosophie à vif" - , organized at the Theatre de la Tempête, in June 2014. In this text, the author presents the question of pleonexia - desire to possess always more - as crucial for understanding the actual world, which is characterized by hyper-concentration of revenue. To address this issue, Dufour selected for this event four philosophical texts witch have been adapted and re-written to be read by great comedians: two texts of Plato (The Republic and Gorgias); The Fable of the Bees, by Mandeville; the fourth text, written by himself, was createn as an encounter between Socrates and his interlocutor today to make a balance. Finally, the annex presents an exclusive text translated for the first time in French by the romanian philosopher Dimitre Cantemir, whose original date from 1705, and contains an important reflection about the pleonexia.

Keywords: pleonexia; "more of..."; pulsionnality; psyche; soul structure; excess; contemporaneity. 


\section{A pleonexia, o que é?}

Dany-Robert Dufour

É uma noção que vem de longe. Do coração da civilização ocidental. De fato, é no mais profundo da Grécia antiga, a partir do fim do período arcaico e no início do período clássico, próximo a -550, que foi identificada uma tendência profunda da alma humana: querer mais do que a sua parte. Os trabalhos do grande helenista Jean-Pierre Vernant atestam isso. Em As Origens do pensamento grego, ele mostra perfeitamente contra o que a filosofia teve que se constituir. Contra a pleonexia. De fato, se a filosofia é necessária, é porque sem ela e sem a ascese que ela permite, nós ficamos em um estado em que:

A riqueza substitui todos os valores [...] porque ela pode tudo adquirir [...]. É então o dinheiro que conta, o dinheiro que faz o homem. Assim, ao contrário de todas as outras "potências", a riqueza não comporta nenhum limite: não há nada nela que possa marcar seu termo, demarcá-la, conclui-la. A essência da riqueza é a desmedida; ela é a própria figura que toma a hybris no mundo. Das fórmulas de Sólon passadas a provérbios, "Não há termo para a riqueza" [...] fazem eco as palavras do poeta Teógnis: "Aqueles que mais têm hoje cobiçam o dobro. A riqueza, ta chrémata, torna-se no homem loucura, aphrosuné [...]". Na raiz da riqueza, descobre-se uma natureza viciada, uma vontade desviada e ruim, uma pleonexia: desejo de ter mais do que os outros, mais que sua parte, toda a parte. (Vernant, 1962 , p. 80-81)

Portanto, a pleonexia pertence a uma forma de hybris, isto é, de desmesura. A hybris é uma noção ainda mais antiga que a pleonexia. De fato, nós a encontramos, antes da filosofia, nos mitos gregos fundadores. Estes mitos gregos se estabelecem, de certo modo, como o discurso da physis, a qual corresponde às forças da natureza com as quais os homens devem criar. Portanto, os nomes comuns se tornam, no mito, nomes próprios. De modo que a deusa Hybris, filha da Noite e de Érebo (divindade infernal nascida do Caos), personifica a hybris, a desmesura. Aprendemos, por meio do mito, que Hybris forma casal com Nêmesis, a punição. Porque aquele que sai de seu limite, se expõe a ser punido pelos deuses para ser mais ou menos brutalmente levado para a medida, a fim de que, de alguma forma, seja reposto em seu lugar, que é o de ser mortal.

É assim que encontramos nos mitos gregos muitos personagens em hybris, que, como tais, sofreram uma punição. Por exemplo, Prometeu, sobre o qual nós devemos uma versão da história a Hesíodo. Era um deus, certamente, mas um deus caído da antiga geração, a dos Titãs, vencidos pelos Olímpicos, de modo que ele também teve que ser reposto em seu lugar. Prometeu, sabemos, 
tinha roubado dos Olímpicos o "fogo sagrado" (o saber divino) para dá-los aos homens. Esse atravessamento do limite lhe valeu a condenação de Zeus: ser acorrentado em uma rocha do monte Cáucaso para que, a cada dia, seu fígado seja devorado pela Águia e para que, a cada noite, ele se reconstituísse. Ou Tântalo que, segundo Píndaro, também tinha roubado dos deuses a ambrósia, na ocasião, para dar seus pratos divinos aos mortais. Por isso, ele será castigado, por sua vez, por esta bonita tortura: ele é colocado no meio de um curso de água e sob árvores frutíferas: quando ele se abaixa para beber, o rio seca, e quando ele se recupera para pegar uma fruta, o vento afasta os ramos da árvore. Ou ainda Ícaro, castigado por subir alto demais e se aproximar perto demais do sol. Ou ainda um personagem que as ciências humanas e sociais conhecem bem, já que ele se chama Édipo. Édipo, cujo gesto - sair da roda da sucessão das gerações para se aliar a sua mãe desencadeou duas punições: a que ele administra em si mesmo se cegando e a que sofreu sua descendência, tornada maldita.

É necessário crer que o encadeamento proeza de hybris-punição ficou no coração da cultura ocidental, já que encontramos o mesmo mecanismo no fundamento das teorias antropológicas do século XX, com a interdição da correspondência de relações de aliança e das relações de filiação (a famosa proibição do incesto); interdição que ordena, segundo Lévi-Strauss (1949), todas as formas de parentesco, também diversas, quaisquer que sejam.

Essas considerações permitem pensar que existe uma relação imensa entre a proibição do incesto e a proibição da pleonexia. Por quê? Porque ambos são excessos. O primeiro tem relação com o serdaquele que, não se limitando ao seu lugar na sucessão das gerações, é punido. O segundo tem relação com o ter daquele que quer mais que a sua parte. Assim, a busca da riqueza sem limites, ta chrémata, tornando-se loucura no homem, aphrosunè, desencadeia também um ciclo de punições que ameaçam não somente a casa (a de Tebas, no caso), mas, também e sobretudo, toda cidade que a teria autorizado.

É justamente esta questão que está no coração do primeiro diálogo apresentado neste livro. A pleonexia, se ela é tolerada na cidade, produz como consequência a punição. Na circunstância, uma crise política, moral e social que testemunha um conflito interno na cidade, notoriamente entre os ricos e os menos ricos. A discordância que se segue então é tão grave que ela pode desembocar na guerra civil, a stasis que, a termo, leva à decadência da cidade. Essa questão é tão próxima do que está em jogo em seu cerne que Platão, no último de seus diálogos, As Leis, retorna para as causas da stasis. No livro V, o Ateniense, isto é, o próprio Platão, se faz legislador e sustenta:

Eu quero editar uma lei sob a seguinte forma: em uma cidade que deve estar abrigada da doença mais grave, eu quero dizer a sedição, que será melhor nomeada como dissensão ${ }^{3}$, não deve haver alguns cidadãos sofrendo de pobreza, enquanto outros são ricos, porque estes dois estados são causas de dissensões. O legislador fixará então um limite a cada um deles; o da pobreza será o valor médio mais baixo 
[...]. O legislador permitirá adquirir o dobro, o triplo e mesmo o quádruplo. Mas aquele que possuir bens que ultrapassarão esta medida [...], deverá dar ao Estado e aos deuses protetores do Estado. Assim, ele estará honrado e escapará da multa. Se ele não se submeter a essa lei, aquele que quiser denunciá-lo terá a metade deste excedente, a outra metade irá para os deuses, e o culpado pagará, além disso, uma multa igual àquilo que ele possui em excesso. (Platão, 744d-744e)4.

Mas o primeiro diálogo vai ainda mais longe, já que ele mostra que, se não é em direção à guerra civil interna que se desemboca, é em direção à guerra externa (com outra cidade), pois a busca sem freio pela riqueza conduz ao desejo de conquistar - por todos os meios possíveis, inclusive a guerra - as fontes e os bens de uma ou de várias cidades vizinhas. A pleonexia leva, portanto, a dois tipos possíveis de consequências catastróficas: primeiramente, a stasis, isto é, a guerra no interior da cidade; em segundo lugar, o polémos, que designa a guerra contra um inimigo exterior. Podemos dizer, portanto, que nossa civilização ocidental, desde a sua origem grega, compreendeu que ela deveria conter esta forma, no duplo sentido do termo: a pleonexia está presente e ela deve ser controlada. Mais ainda: é justamente porque ela está necessariamente presente, que ela deve ser controlada.

Mas por que ela está presente? O segundo diálogo responde precisamente a esta questão. Porque esta forma, a pleonexia, não existe, inicialmente, em nenhum outro lugar que não seja na própria alma.

A alma, a psyché, é, de fato, constituída por Platão por três partes. É no épithumétikon (ou "alma de baixo", situada no baixo ventre) que nascem as épithumiai, as paixões. Este épithumétikon deve ser temperado e disciplinado pelo logistikon (frequentemente chamado "alma de cima"), sede do logos. A razão desta luta entre a terceira e a primeira alma é a alma intermediária, o thumos, o elemento irascível, situado no coração. Ele é suscetível de acessos e de cóleras devastadoras no momento em que domina a alma de baixo, mas é igualmente capaz da coragem que faz os heróis, os heróis da cidade, no momento em que é colocado a serviço da alma de cima. Portanto, o thumos é um elemento deslizante que pode versar tanto do lado do épithumétikon, quanto do lado do logistikon, quer dizer, ou do lado disso que chamamos hoje de pulsionalidade, ou do lado da simbolicidade.

É decisivo notar aqui que o termo "paixão" não tem o sentido positivo que nós conhecemos hoje. Tomamos facilmente a medida quando mencionamos que "paixão" se diz em grego pathos, o que significa "sofrimento"; sentido que a palavra guardou até o século XIX e mantém, às vezes ainda, como na expressão "a Paixão de Cristo", o que, que eu saiba, não significa que Cristo tenha se divertido bem "vivendo suas paixões", como se diz hoje em dia, mas sim que ele sofreu. Portanto, de fato, pathos, como seu equivalente latino passio, significa "alguma coisa que chega a um homem", alguma coisa da qual ele é uma vítima passiva. Aristóteles, por exemplo, compara o homem em um 
momento de paixão a uma pessoa adormecida, demente ou bêbada: sua razão está como que suspensa ${ }^{5}$. Ele não é mais agente (aquele que age), ele é paciente, aquele que padece (milagre da clareza lexical: todos estes termos, pathos, paixão, passivo, padecer [pâtir], paciente, são da mesma raiz e se encadeiam uns aos outros).

Esta percepção negativa da paixão não é particular a Platão, nós a encontramos por todos os lugares nos textos da Grécia Antiga. Por exemplo, em Xenófanes, que na Economia, diz que os destemperados, aqueles que são movidos por seus épithumiai, "são escravos de senhores verdadeiramente duros [...]. Estes reinam tão duramente sobre os homens que vem a dominá-los, ao vê-los jovens e capazes de trabalhar, eles os forçam a lhes trazer todo o fruto de seu trabalho" (I-22).

Se é absolutamente preciso alguma coisa para contrabalançar a paixão (ou a pulsão que, como tal, impulsiona a querer sempre mais), é porque a paixão possui uma estrutura muito especial. Ela é, de fato, "sem limites". Aristóteles o explica muito bem, em Ética a Nicômano: "A pulsão é insaciáve/ e tudo a excita no ser desprovido de razão; o exercício da luxúria aumenta a força inicial, e se estas luxúrias são grandes e em número excessivo, elas podem ir até excluírem a reflexão" (Aristóteles, 322 a.C., III-15. 1119 b3). Assim, o que descreve melhor este lado sem limites da pulsão é justamente o termo pleonexia, que será utilizado por todos os filósofos do século IV, como se fosse aí, no momento de um grande desenvolvimento da cidade grega, o problema principal a resolver ${ }^{6}$. No diálogo apresentado aqui, Sócrates utiliza uma imagem para descrever esta ilimitação da pulsão. Ele compara aquilo que se deixa ir para querer sempre mais a "tarambola", este pássaro que come e que defeca ao mesmo tempo. Porque ele nunca tem o suficiente. Podemos dizer de outro modo hoje: o pleonéxico, aquele que quer sempre mais (dinheiro, no caso) é um "adicto". Um adicto que, como o drogado, quer sempre mais, porque ele está sempre em falta. Aí também vemos perfilar no horizonte a punição: a destruição, mesmo a autodestruição, do destemperado. 0 thumos, elemento irascível, no pleonéxico, se coloca a serviço da alma de baixo e se transforma no furor de querer sempre mais, até destruir tudo em torno dele, inclusive ele mesmo. Se o primeiro diálogo enfatizava a destruição da cidade, o segundo acrescenta a isso um outro plano: a autodestruição.

Eu não tenho tempo de desenvolver aqui este ponto, mas eu peço ao leitor que note a grande constante com a qual descrevemos no Ocidente, de Platão a Freud, a estrutura tripartite da alma7: épithumétikon/thumos/logistikon, de um lado, e isso/ supereu/ eu, do outro. Essas duas séries são, de fato, próximas: 1) o isso (reserva pulsional) corresponde, sem contestação possível, a épithumétikon; 2) quanto ao eu (o Ich freudiano), ele próprio herdado do logistikon grego, lugar da deliberação crítica; 3) enfim, o thumos e o supereu apresentam a mesma clivagem: cada um possui uma face repressiva ("Você deve limitar sua pulsão" - o que Freud desenvolverá longamente no texto Mal-estar na civilização), e uma face incitativa que intima o sujeito a não se deter aonde quer que ele chegue (Lacan, 1986[1959-1960], p. 13), que desenvolveu este aspecto, fala então da face "feroz e obscena" do supereu). É, portanto, sempre uma maquinaria psíquica ternária que deve 
conter (no duplo sentido deste verbo) aquilo de que ela se alimenta: o excesso pleonéxico inicial. Se não a máquina explode.

Assim, justamente, chegou um momento em que, na história ocidental, o supereu-thumos se alinhou ao "isso" para ditar aos sujeitos o imperativo do gozo. É o objeto do terceiro texto, $A$ Fábula das abelhas, de Mandeville (1705). Neste texto, Mandeville, precursor do iluminismo inglês, clama que nós devemos passar da ideia (antiga) de controlar a pleonexia inerente ao desejo humano, à ideia (moderna) de liberá-la; sob a justificativa de que isso traria a todos a riqueza. Seria preciso, segundo a célebre fórmula de Mandeville, liberar os "vícios privados" para que a "virtude pública" (a riqueza) advenha.

O texto de Mandeville é muito importante, já que ele permite estabelecer um laço entre a economia psíquica (a liberação das paixões e das pulsões) e a economia dos bens (aumento da riqueza).

Segundo minha hipótese, é nesta equação que se fundou o liberalismo (econômico), que diz (e diz sempre mais à medida que se torna sempre mais ultraliberal) que a riqueza (e, portanto, a felicidade do maior número) somente pode provir da suspensão da proibição das paixões em geral e da pleonexia em particular ${ }^{8}$.

No quarto diálogo, da fascinação socrática, escrito por mim, Sócrates interroga, na sua usual maneira irônica, esta equação: a suspensão da proibição da pleonexia não conduziria, mais do que à felicidade do maior número, à formação de uma hiperclasse, cada vez mais reduzida, caracterizada pela hiperconcentração da riqueza, e de uma hipoclasse, cada vez mais numerosa, sujeita à pauperização? A questão merece ser colocada quando se sabe que hoje, nas democracias modernas (onde nós estamos, digamos, todos livres, diferentemente da democracia antiga, reservada somente aos cidadãos), a distância entre os salários pode ir de 1 a 1000 (com os prêmios), e infinitamente mais se englobamos os rendimentos financeiros, enquanto que Platão, em As Leis, como vimos, preconizava uma distância máxima dos patrimônios pertencentes aos homens livres indo de 1 a 4. Esta comparação permite, de passagem, medir os "progressos" alcançados em 2500 anos e de se perguntar se a escravidão está realmente abolida!

Este diálogo se inspira, de fato, na grande lição sobre a pleonexia dada, involuntariamente, por Alan Greenspan, o antigo presidente ultraliberal da onipotente Reserva Federal americana (FED), geralmente designada sob o nome de "o economista dos economistas" ou o "Maestro", ou mesmo o "Oráculo". Na sequência da primeira grande crise do ultraliberalismo", a de 2008, Alan Greenspan, um dos maiores responsáveis desta crise, foi interrogado, em 23 de outubro de 2008, pela comissão dos Estados Unidos encarregada do controle da ação governamental. É um documento extraordinário, pois vemos como a grandiloquência se transforma em lamentável derrota no momento em que o real retorna e que os sofismas afundam ${ }^{10}$. 0 "Oráculo" admitiu que a crise atual recolocava em causa a superioridade de um sistema, o do free Market, no qual ele tinha sempre 
acreditado: "Sim, eu encontrei uma falha. Eu não sei até que ponto ela é significativa e durável, mas isso me fez mergulhar em uma grande confusão".

O presidente da comissão, Henry Waxman, vinha lembrando a Greenspan os propósitos que ele tinha situado no passado, segundo os quais, "os mercados livres e concorrenciais são de longe a melhor maneira de organizar as economias, sem equivalente". O antigo patrão da FED admitiu, então, ter "cometido um erro acreditando que o sentido de seus próprios interesses, notoriamente o dos banqueiros, era a melhor proteção". A expressão "sentido de seus próprios interesses" é, evidentemente, compreensível como vontade pleonéxica. "Em outros termos, você percebe que a sua visão de mundo, a sua ideologia, não é a melhor, não funcionava?", acrescentou Waxman. "Absolutamente, exatamente", respondeu Greenspan. "É precisamente a razão pela qual estou chocado, porque fazia quarenta anos ou mesmo mais que de maneira muito evidente isso funcionava excepcionalmente bem".

É possível então que, por uma vez, o oráculo não tenha se enganado: a pleonexia, ela não funciona. Entretanto, ela continua, após a crise de 2008, a constituir o princípio sobre o qual tudo é fundado. Não somente a economia financeira e, em sua sequência, a produção, são fundadas, segundo o próprio Alan Greenspan, na avidez dos banqueiros. Mas também o consumo. O mercado não é, de fato, esta instância que promete oferecer (isto é, vender) constantemente a cada um todo objeto manufaturado, todo servido comercial, todo fantasma produzido pelas indústrias culturais a fim de satisfazer todas as apetências sejam elas quais forem? Se isso é verdade, então podemos dizer que a civilização ocidental passou de uma necessidade de controle das paixões e das pulsões à exploração industrial da alma de baixo. Podemos falar aqui de uma virada libidinal do capitalismo ${ }^{11}$.

A pleonexia, então, estaria no coração do sistema: o querer sempre mais da oligarquia financeira explora o querer sempre mais dos objetos dos indivíduos assim reduzidos a puros e simples consumidores, o que obriga a explorar ainda mais todas as fontes, polui tudo e perturba gravemente os equilíbrios ecológicos fundamentais.

É aí onde a velha questão da punição ressurge: o princípio pleonéxico creditado pelo Ocidente, tendo ganhado o mundo (a globalização atual), se transforma em ameaça de destruição deste mundo. Quando a pulsão não se simboliza mais, ela se transforma em pulsão de morte.

Falei muito sobre os fundamentos do Ocidente, como se só a Grécia antiga, forte em sua filosofia, tivesse sabido colocar o problema da pleonexia e avançar na única solução viável: controlála. De fato, esta necessidade de controle da pleonexia aparece também nas sabedorias populares, estas filosofias práticas, absolutamente espontâneas. Nós aprendemos sobre isso com Marcel Mauss (1950[1904]): ele não hesita em falar de um "horror à pleonexia" nas sociedades "tradicionais". A passagem na qual Marcel Mauss emprega esta expressão muito forte merece ser longamente citada. Ela se origina de suas observações (indiretas) nas populações esquimós (hoje chamadas Intui, indo do Alasca à Groelândia): 
Em toda a Groelândia, quando os recursos de uma casa ultrapassam o nível do que é considerado como normal, os ricos devem obrigatoriamente emprestar aos pobres [...] Este horror à pleonexia é também muito desenvolvido nas regiões centrais. Ele é marcado mais especialmente pelas trocas rituais de presentes, na ocasião das festas de Sedna, presentes dos homônimos dos ancestrais mortos, distribuição às crianças, visitantes, etc. A combinação deste rito com os costumes indianos do noroeste conduzem, nessas tribos do Alasca, a uma instituição, não idêntica sem dúvida, mas análoga ao potlatch das tribos Indianas. A maior parte dos vilarejos desta região possuem tipos de chefes, cuja autoridade é, aliás, mal definida, e, em todo caso, um certo número de homens ricos e influentes. Mas a comunidade fica enciumada com seu poder; e o chefe não permanece chefe, ou antes, o rico só permanece rico e influente na condição de distribuir periodicamente seus bens. A benevolência única de seu grupo Ihe permite esta acumulação e é pela dissipação que ele a conquista. Assim, alternativamente, ele goza de sua fortuna e a expia, e a expiação é a condição do gozo. O senhor Nelson nos fala mesmo dos chefes que foram assassinados, porque eles eram ricos demais [...]. Isso mostra, [conclui Mauss] o alto grau de unidade moral a que alcança, neste momento, a comunidade esquimó. (Mauss, 1904/1950, p. 467-468)

Portanto, o rico devia expiar regularmente sua fortuna, porque "a expiação [era lá] condição do gozo [de seus bens]"; este esquema será retomado por Georges Bataille (1949), que evoca uma "parte maldita", esta parte a mais, isto é, em excesso, levada para o outro, no momento em que ela não é tomada, expiada, dissipada no e pelo consumo, na e pela festa, no e pelo sacrifício, e mesmo na e pela guerra. Em suma, se havia o ato pleonéxico, então era necessário expiar o horror dele. Um horror que Mauss situou bem para compreender. Por quê? Porque a pleonexia interrompe o ciclo ternário da troca nessas sociedades: o pleonéxico não quer mais "dar, receber, devolver", mas simplesmente "tomar". O que coloca o risco de engatá-lo no ciclo "tomar, recusar, manter", esta simétrica negativa do dom maussaniano, de que fala Alain Caillé (2007, p. 263), em Anthropologie du don. É um movimento no qual há acumulação, uma retenção do dom, uma recusa da troca e uma tensão sobre o que é mantido, que poderia ser pensado como um dos tempos prévios, necessários à acumulação capitalista primitiva.

Já que falamos da pleonexia, preciso acrescentar a estes quatro textos algo a mais. No caso, um texto não lido nas jornadas "Philosofie à vif", de La Tempête. Um bônus, portanto. Trata-se de um surpreendente texto do filósofo romeno Dimitrie Cantemir (1723/1973) retirado de L'Histoire hiéroglyohique (publicado em 1705 e inédito na França), que descreve de uma maneira muito barroca como funciona, e com quais manobras, o famoso templo da deusa Pleonexis, erigido na boa cidade de Épithumia. 
Portanto, a se notar que, por um desses curiosos (e significativos) acasos da história, é no momento exato (1705) em que Mandeville faz da pleonexia o remédio para todos os males que Cantemir, na pura tradição grega, a estigmatiza infinitamente.

Mas quem é este Dimitrie Cantemir? E, primeiramente, por que ele é tão pouco conhecido na história intelectual ocidental? Seria porque ele é um pensador menor, ou porque ele vem de um pequeno país da Europa, linguisticamente dominado (a Moldávia, da qual uma parte está atualmente ligada à Romênia)? A resposta é simples: é um pensador maior, mas que vem de uma região e de uma língua não centrais. De fato, é simplesmente o maior pensador romeno, equivalente a um Voltaire, que, aliás, o tinha em alta estima. Cantemir é não somente filósofo enciclopedista, mas também compositor ${ }^{12}$, músico ${ }^{13}$, escritor, matemático, arquiteto, historiador, cartógrafo e, além disso, soberano (príncipe herdeiro de Moldávia, depois tornado príncipe do império russo pelo tsar Pedro, o Grande ${ }^{14}$ ). Ele praticava doze línguas, tanto modernas quanto antigas (das quais o grego, como testemunham seus usos criativos de noções centrais, como épithumia e pléonexia). Soberano, ele buscou libertar seu país da tutela turca. Assim, ele precisou sofrer. De fato, ele conhecia bem o Império otomano, já que, enquanto príncipe da Moldávia, ele tinha sido "convidado" (quer dizer, mantido refém), durante mais de vinte anos, em Constantinopla, constrangido a olhar a "Sublime Porta" - nome pelo qual se designa o Império turco, em referência à porta de honra monumental da sede do governo do sultão.

Cantemir revela, nesse texto, o princípio sobre o qual funciona um império ainda fundado sobre um potente comércio, mas já em decadência. Nós não estamos mais, de fato, na época de Solimão, o Magnífico (que reinou de 1520 até sua morte, em 1566): o Império otomano perdeu sua face soberba frente às potências europeias enriquecidas pela conquista do Novo Mundo e pela apropriação e pela exploração de seus recursos (dentre as quais o ouro). Para analisar o que vê, Cantemir coloca em jogo uma das ideias principais do mercantilismo (teoria econômica em vigor na época, que ele conhecia bem), segundo a qual "o dinheiro é capaz de gerar filhotes".

Ele situa a ação de seu romance, L'Histoire hiéroglyphique, do qual é tirado esse excerto, em uma paisagem fantástica traçada de arquiteturas barrocas de onde surgem animais fabulosos. Este contexto fantasmagórico é propício a todas as magias, das quais uma, notoriamente: lá, o dinheiro pode se autocriar. Não seria exagero dizer que, neste texto, Cantemir antecipe alguma coisa como... Las Vegas e seu kitch no momento em que ele olha a Sublime Porta, porque ele já a vê como algo que abre uma espécie de economia-cassino.

A ideia do possível autoengendramento do dinheiro será, sabemos, retomada em novos ventos por Marx, cento e cinquenta anos mais tarde. Em O Capital, Marx fala, de fato, do "dinheiro que produz dinheiro [...] A moeda que gera filhotes". Sendo este movimento a partir do qual se cria o capital ${ }^{15}$.

Se o texto de Cantemir é tão interessante, é porque ele revela alguns dos grandes "truques" que permitem, justamente, que o dinheiro faça dinheiro. Ele explica, assim, que a deusa Pleonexis 
é, de fato, satisfeita (o que lhe permite demandar um tributo) a cada vez que alguém pode transformar alguma coisa em dinheiro; mesmo da terra (o que seguramente não teria sido repudiado pelos fisiocratas). Da terra, portanto, e por que não de algo ainda pior? Da merda, por exemplo. Como, de fato, não pensar aqui em Freud, que fazia da merda a própria essência do dinheiro ${ }^{16}$ ? Porque tudo pode, graças às práticas alquímicas da deusa Pleonexis, se transformar em ouro. Tudo, mesmo aquilo que ainda escapa ao comércio, como o que ainda está desprovido de valor, ou como o fato de falar para dizer um simples bom dia, ou o fato de pedir uma informação ou seu caminho a um alter ego. De fato, é preciso retirar de cada troca (comercial, amistosa, verbal, amorosa, social...) uma comissão. O princípio é o seguinte: propomos ao outro vento, ou uma ilusão qualquer, ou uma promessa de ganho superior ao lance dado, ou um produto milagroso, ou um reconforto, ou um suposto passe livre, ou um serviço qualquer, ou um suposto favorecimento, e the pedimos dinheiro em contrapartida. E se o outro paga, é porque acredita que seu lance pode lhe render mais do que custou. Nesse mercado de tolos, pode-se mesmo até esfolar um piolho para vender sua pele ou (como no texto de Cantemir) esvaziar um carrapato para tirar dele um bom preço de sangue (evidentemente contaminado) que seu bolso contém - porque não há pequenos benefícios. Nós nadamos aqui no que Marx chamará mais tarde "as águas geladas [e corrompidas] do cálculo egoísta". O príncipe Cantemir, formado pelos códigos de honra, na justiça cavalheiresca e na dignidade pessoal, teve que sofrer muito com as abomináveis (e satânicas) regras decretadas pela deusa Pleonexis (que ele chama de seus "oráculos") para comandar no mundo mantido pela Sublime Porta, do qual ele era prisioneiro.

Hoje, na época da globalização ultraliberal desregulada, estas práticas pleonáxicas perduram e mesmo se expandem. Além do nome clássico de bakchich, utilizado no texto (palavra persa, passada ao árabe, depois ao turco), nós os nomeamos mais adiante de múltiplas formas: propina, securitização de dívidas passadas, hedge funds, permitindo especular na baixa e na alta sobre a evolução dos mercados, manipulações contábeis, manipulações de preços de transferências, fraude e evasão fiscais pelas filiais offshore e sociedades-fantasmas instaladas em "paraísos fiscais", desvios de créditos públicos e mercados manipulados, corrupção e comissões ocultas, enriquecimento sem causa e abuso dos bens sociais, vigilância e espionagem, chantagem e delação, violação dos regulamentos em matéria de direito do trabalho e de liberdade sindical, de higiene e de segurança, de cotizações sociais, de poluição e de ambiente, comissão, retrocomissão ${ }^{17}$ - sem esquecer a... retro-omissão (a qual ocorre quando o novo presidente, horrorizado, para de pagar as comissões e retrocomissões estabelecidos pelo anterior $\left.{ }^{18}\right)$.

Em suma, nestas sublimes economias, não se para de colocar e recolocar, esperando, como em um jogo, o retorno do investimento, e mesmo, tanto quanto possível, a bolada. Nenhuma dúvida de que hoje nós tenhamos chegado ao estado supremo da pleonexia, já que o capitalismo é constituído pelo conjunto dessas transações onde cada um tenta ter mais do que a sua parte. Será muito necessário nos darmos conta um dia (tarde demais, talvez) de que o capitalismo funciona 
como um emaranhado de sistemas de Ponzi. O que, sabemos, designa estas montagens financeiras, na qual os primeiros investidores são remunerados graças aos fundos trazidos pelos seguintes, e assim sucessivamente, até que todas as retiradas possíveis sejam feitas e que o sistema imploda. No momento em que morre a bolha especulativa assim criada, ela provoca uma destas "crises cíclicas" que conhece o capitalismo. Uma crise só se acalma quando outras bolhas se formam. E assim sucessivamente.

Poder-se-ia dizer que Marx, que conhecia alguns textos de Cantemir ${ }^{19}$, impulsionou, de algum modo, em um degrau, a hipótese do príncipe moldavo, aplicando-a no próprio coração do Capital. A grande descoberta de Marx é, de fato, enunciável assim: o capitalismo e seus emaranhados "pônzicos" repousam sobre um embuste modelo, especial e original, no que se refere à "força de trabalho". O capitalista é aquele que, como bom pleonéxico, compreendeu que a compra desta força traz mais do que ela custa: ele retira dela a mais-valia, fonte do Capital, sobre o que todo o edifício repousa.

Vemos o interesse neste texto de Cantemir, já que ele permite explorar algo como a lógica geral do embuste... que Marx, mais tarde, descobrirá no coração do capitalismo, na e pela análise da força de trabalho.

Como o leitor poderia ficar agradecido por se dizer um pouco mais sobre a questão, podemos tomar um exemplo de transação feita exatamente para ludibriar qualquer pessoa crédula. Eis, portanto, um "pequeno anúncio" assim lido: "Você quer se tornar rico? Sim. Então me envie 50 euros e eu lhe darei a receita infalível para aceder à riqueza. Note bem: Reembolso garantido em caso de não-funcionamento".

O leitor aliciado por este anúncio, se tentar sua sorte, receberá, em alguns dias, a seguinte resposta:

Obrigado por sua carta e pela nota que ela continha. Posso lhe dizer agora: cada vez que faço esse anúncio, eu recebo por volta de mil cartas implorando que eu forneça a famosa receita. E como sou muito honesto e faço questão de honrar meus compromissos, eu respondo sempre a cada uma dizendo: "A receita, eu já Ihe dei no momento e que eu o convidei a jogar. Mas, se você não entendeu ainda, posso ser mais explícito: Faça como eu, publique um anúncio dizendo que você vai fornecer, por uma bagatela, o segredo para se tornar rico e... você se tornará rico!"20.

É precisamente uma moral e oráculos desse tipo que difunde o templo da deusa Pleonexis. Em 1705, nos primórdios da primeira revolução industrial, eles serão, portanto, discutidos nos dois extremos geográficos da Europa. Mandeville, na Inglaterra, verá em sua aplicação generalizada a possibilidade de alcançar a riqueza infinita. E Cantemir, na Romênia, compreenderá o oráculo pleonéxico como um operador de transformação da sociedade em uma degradante sala de jogo. 
Que os textos a seguir possam então trazer um pouco de luz sobre o desejo pleonéxico, inerente ao homem, e o que convém fazer dele nos dias de hoje. É certo que, ao longo destes três últimos séculos, este desejo, liberado, permitiu o aumento, senão da felicidade, ao menos da riqueza (sobretudo para alguns). Mas hoje, parece que perseverar em um querer-ter-sempre-mais pode colocar em causa a perenidade do mundo por um aumento muito perigoso dos riscos:

1) de guerras civis (stasis), opondo os pobres aos ricos;

2) de guerras externas (polémos) entre beligerantes em competição para ter mais ou para dominar mais;

3) de desregulação da psyché, isto é, danos psicopatológicos dos indivíduos resultante de um apoio cada vez mais forte na alma de baixo, o epithumetikon. O que se traduz por uma prevalência da pulsionalidade sobre a simbolicidade cujo saldo, com frequência, é uma multiplicação de passagens ao ato contra si e/ou contra os outros;

4) de perturbações dramáticas do que os antigos chamavam de cosmos. Para dizê-lo de outro modo, os equilíbrios metaestáveis da vida na terra são perturbados pelos efeitos de uma exploração excessiva dos recursos e dos bens comuns (água, ar...). Sócrates, no Gorgias, já insistia nesse ponto junto a Cálicles:

O céu e a terra, os deuses [o que quer dizer, no politeísmo grego, as forças da natureza] e os homens estão ligados por uma comunidade, feita de amizade e de um bom arranjo, de sabedoria e de espírito de justiça, e é a razão pela qual, a este universo, se dá o nome de kósmos ["mundo ordenado" em grego] que quer o arranjo, e não o desarranjo, e menos ainda a desregulação. (Platão, 507e-508a)

Tradução: Flávia Lana Garcia de Oliveira Revisão: Marília Amorim e Tania Coelho dos Santos

\section{Notas:}

${ }^{1}$ Dufour, D.-R. (2015). Pléonexie [dict.: "Vouloir posséder toujours plus"] (pp. 15-40). Lormont: Le Bord de l'Eau.

N.A.: Um amigo, leitor do manuscrito deste livro, me assinalou que o título deste primeiro capítulo era um pouco feio. Imediatamente concordei com isso... sem, contudo, renunciar a este título, mas sim o contrário. Por quê? Porque eu quis que o leitor percebesse que este "o que é" [qu'est-ce] se entende como "caixa" [caisse]. Não seria aí uma homofonia perfeita para tirar proveito, pois permite imaginar que a pleonexia implica sempre um caixa, ou um fundo para acumular o excedente que ele visa produzir.

N.T.: Perde-se na tradução para o português o jogo homofônico produzido na língua francesa, já que "qu'est-ce" [o que é] e "caisse" [caixa] são palavras de pronúncia semelhante. 
${ }^{2}$ Dany-Robert Dufour Publicou diversas obras sobre as formas de subjetivação e de socialização. Há cerca de quinze anos se dedica a uma antropologia crítica do liberalismo.

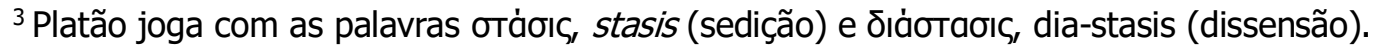

${ }^{4}$ Sobre esta noção de stasis, ver os trabalhos decisivos de Nicole Loraux. Loraux, N. (1997). La Cité divisée. Paris: Payot.

${ }^{5}$ Ver Dodds, E. R. (1959/1977). Les Grecs et l'irrationnel. Paris: Flammation, p. 185.

${ }^{6}$ Ver Bouchet, C. (2007). La pleonexia chez Isocrate. Revue des études anciennes, (109), 475-489.

Paris: Université Bordeaux Montaigne.

${ }^{7}$ Isso faz pensar que a teoria grega da alma e sua estrutura em três níveis foram tão bem transmitidas ao longo da história ocidental que se pode reencontrá-las em Freud. Podemos dizê-lo de outra forma: Freud somente pôde forjar sua teoria revolucionária, psico-análise, retornando aos fundamentos gregos da psyché. Fundamentos aos quais ele tinha sido introduzido durante sua formação (e notoriamente entre 1873 e 1876) por seu professor na universidade de Viena, o filósofo Franz Brentano, excelente conhecedor da psyché grega. Um encontro tão marcante que Freud chegou a pensar em poder fazer uma tese de filosofia com Bretano... antes de perceber que este recusava a hipótese do inconsciente.

${ }^{8}$ Sobre este ponto, me permito remeter a meu livro, Dufour, D.-R. (2009/2013). A cidade perversa: liberalismo e pornografia. Rio de Janeiro: Civilização Brasileira.

${ }^{9}$ Digo a "primeira crise" porque as outras - não apenas financeiras, mas também sociais, políticas, ecológicas... - já se perfilam no horizonte.

${ }^{10}$ Podemos encontrar este documento no site do governo americano: "Testimony of Dr. Alan Greenspan". Commitree of Gouvernment Oversight and Reform, 23 de outubro de 2008.

11 Permito-me remeter a um estudo recente: D.-R. Dufour. (2014). Le tournant libidinal du capitalisme. Revue du MAUSS semestrielle (44), 27-46. Paris: La Découverte.

12 Se sua filosofia é mal conhecida, sua música é sempre tocada. Por exemplo, pelo grande especialista da música barroca, Jordi Savall e seu conjunto Hespèrion XXI. Ver: Cantemir, D. (2009). Istanbul. The Book of the Science of Music. Alia Vox.

${ }^{13}$ Ele era um intérprete famoso de tanbur, um tipo de alaúde longo.

${ }^{14}$ Uma biografia recente começou a reparar o esquecimento de que sofre Cantemir. Ver: Lemny, S. (2009). Les Cantemir. L'aventure européenne d'une famille princière au XVIIIe siècle. Paris: Complexe.

${ }^{15}$ Marx, K. (1876/2012). Como o dinheiro se transforma em capital. O capital. Livro I, tomo II, capítulo IV. São Paulo: Veneta.

${ }^{16}$ Ver: Freud, S. (2002). La Vie sexuelle. Paris: PUF \& Freud, S. (2002). Névrose, psychose et perversion. Paris: PUF.

${ }^{17}$ Encontramos nesta lista os motivos dos escândalos Enron, Vivendi e outros, ocorridos no início dos anos 2000, anunciadores da grande crise de 2008. 
${ }^{18}$ Exemplo: Jacques Chirac teria parado, a partir de sua eleição em maio de 1995, de pagar as retrocomissões ao Paquistão previstas na ocasião de vendas de armas e tendo servido ao financiamento da campanha de seu rival Édouard Balladur. Os militares paquistaneses se vingaram deste confisco pelo atentado de Karachi, que custou a vida de quinze pessoas, das quais onze francesas, em 8 de maio de 2002.

${ }^{19}$ Por exemplo, ele o cita em "Révélations sur I'histoire de la diplomatie secrète au XVIIIe siècle, 1856-1857", texto ante "grande russo" de Marx há muito tempo posto embaixo do tapete pelos comunistas de Moscou e finalmente editado na França: Marx, K. (1954). La Russie et l'Europe. Paris: Gallimard.

${ }^{20}$ Encontramos no Brasil, onde a teologia do sucesso tende a partir de agora a substituir a teologia da libertação dos anos 1960, uma variante desta história. Um homem pobre vai rezar à padroeira do sucesso, santa Expedita. Ao longo de sua prece, a voz da santa ressoa em seu espírito e lhe deixa a seguinte mensagem: "Compre uma medalha me representando e você ficará rico". Para ser tornar não rico, mas muito rico, o homem compra, a crédito, mil medalhas da efígie da santa. Fazendo isso, ele obtém para esta compra em atacado um preço especial e ele começa então a revender cada uma muito caro com a seguinte mensagem: "Se você comprar esta medalha, você pode ficar muito rico". E assim, ele se tornou milionário.

\section{Referências Bibliográficas}

Bataille, G. (1949). La Part maudite. Paris: Minuit.

Bouchet, C. (2007). La pleonexia chez Isocrate. Revue des études anciennes, (109). Paris: Université Bordeaux Montaigne.

Caillé, A. (2007). Anthropologie du don. Paris: La Découverte.

Dodds, E. R. (1959/1977). Les Grecs et l'irrationnel. Paris: Flammation

Freud, S. (1929). Malaise dans la civilisation. Paris: Payot.

Lacan, J. (1986/1959-1960). L'Éthique de la psychanalyse. Paris: Seuil.

Lévi-Strauss, C. (1949/1982). As estruturas elementares do parentesco. Petrópolis: Vozes.

Loraux, N. (1997). La Cité divisée. Paris: Payot.

Mauss, M. (1904/1991). Essai sur les variations saisonnières des societés eskimo. Étude de morphologie sociale (1904). Sociologie et Anthropologie. Paris: PUF.

Platão. (357 e 347 a.C./2010). As Leis. São Paulo: Edipro.

Vernant, J.-P. (1962). Les Origines de la pensée grecque. Paris: PUF.

Citacão/Citation: Dufour, D.-R. (mai. a out. 2015). A pleonexia, o que é?. Revista aSEPHallus de Orientação Lacaniana, 10(20), 24-38. Disponível em www.isepol.com/asephallus. doi: 10.17852/1809709x.2019v10n20p24-38 
Editor do artigo: Tania Coelho dos Santos.

Recebido/Received: 24/10/2015 / 10/24/2015.

Aceito/Accepted: 27/10/2015 / 10/27/2015.

Copyright: (C) 2013 Associação Núcleo Sephora de Pesquisa sobre o moderno e o contemporâneo. Este é um artigo de livre acesso, que permite uso irrestrito, distribuição e reprodução em qualquer meio, desde que o autor e a fonte sejam citados/This is an open-access article, which permites unrestricted use, distribution, and reproduction in any medium, provided the author and source are credited. 